\title{
Challenges and Opportunities of Women Empowerment in Leadership Position in Ethiopia
}

\author{
Nigist Melese \\ Collage of Business and Economics, Department of Accounting and Finance, \\ Madda Walabu University, Ethiopia
}

\begin{abstract}
Today businesses are proving quite challenging, yet ever evolving, with the advancement of technology, innovative opportunities and complex global interactions. These challenges require diverse approaches in terms of perspectives and experiences; this entails recognizing the importance of including more women in leadership positions and roles. It is universally accepted truth that women are the base and fuel for the overall development of a country but their involvement in leadership position is low. Hence, the purpose of this review paper was to examine the challenges and opportunities for Women Empowerment in Leadership Position in Ethiopia. By its methodological approach, this review is considered to be a narrative review since the reviewer summarized the findings of empirical research which were conducted in different parts of Ethiopia, and a total of 13 research findings were reviewed. The findings from these studies revealed that, lack of academic qualification, gender stereotyping, over burden of domestic responsibility, lack of confidence, lack of support at home and work place, religious practice, lack of experience are the main factors that hindered women's empowerment in leadership position in Ethiopia. Moreover, the results from the review also identified the affirmative action, better institutional policy, the development of women's affairs at different level, gender policy strategies, training and developing different software are major prospects of women empowerment in leadership position in Ethiopia.
\end{abstract}

Keywords: challenges, opportunities, women empowerment in leadership, Ethiopia.

DOI: $10.7176 / \mathrm{EJBM} / 11-13-04$

Publication date:May $31^{\text {st }} 2019$

\section{Introduction}

As it is known women have a vital role in the community transformation and in developing transformational leadership in a given country. As per UN Global Compact (2011), ensuring women involvement and representing them in leadership across sectors of all government services is essential to build good governance, transparency, accountability, and to improve the quality of women's life.

Panigrahi (2013), states that the presence of women in leadership position at worldwide brings development, and ensures social justice through gender equity at leadership and decision making levels. Hence, the report of expert group meeting of 2010, believed that women's equal participation in decision- making is not only a demand for simple justice or democracy but can also be seen as a necessary condition for women's interests to be taken into consideration.

However, women are under-represented in decision position in different public sectors; i.e., participation in political, social, economic and leadership is negligible which becomes a challenge to many developing countries (the UN Global Compact, 2011). Especially, women in Africa have been faced with challenges and obstacles to their wellbeing and development including discrimination, marginalization, violence, abuse, deprivation, and exclusion among others (Genet and Habtu, 2011).

Which is not unique to Ethiopia and though the number of women in Ethiopia represents half of the population, their participation of women in leadership and decision making position were totally dominated by men (UNDAF, 2012), Surprisingly, during Haileslassie's regime when the first parliament was introduced, no woman had allowed to be nominated as a member of parliament until 1957, though two women in 1965 and five women in 1969 have joined the emperor's parliament; similarly, though the Derg 1987 constitution and the subsequently proclaimed electoral laws had ensured the equality of citizens and their right to elect and be elected (in principles), in practice these constitutions and electoral laws were far from increasing the participation of women in leadership and decision making activities.

Following this, the government of Ethiopia had adopted some measures to benefit women, i.e, relevant passages in the most recent version of the Constitution of Ethiopia (1995), the Revised Family Law (2000) and the Revised Criminal Code (2005), Ethiopian Women Development and Change Package (2006) and the National Action Plan (NAP-EG) and adoption of MDGs as guiding framework for planning (UNDAF, 2012).

Moreover, following 2018 elections in Ethiopia, a record-breaking number of women now hold leadership positions in the country's government and women assuming leadership positions at the highest levels of government; and able to see a woman president (Addis Ababa, Apr 192019 (IPS). This is important as the intention is to sustain the benefits of the system by both genders, but also ensure both men and women are equally engaged. However at sector and institutional level (i.e. where policy, resourcing and planning are usually 
discussed and decided upon) there are very few female decision-makers; that is why women still struggle to rise up the ranks in other sectors.

As a result, it is rational to conduct a review on the various studies which have been conducted in different corners of the country regarding challenges and opportunities of Women Empowerment in Leadership Position in Ethiopia. It is hoped that this will help to provide a multifaceted input for policy makers, ministry of women affairs, ministry of women and child affairs, ministry of women and youth affairs, different NGO's, and any other concerned bodies. Besides, the reviewer has not come across with any paper related to the topic described, and hence it was considered pertinent to conduct this research in order to fill the gap in reviews, regarding the challenges and opportunities of Women Empowerment in Leadership Position in Ethiopia.

\section{Objective of the review and methodology}

As stated earlier, the core objective of this review paper was to examine the challenges and opportunities for Women Empowerment in Leadership Position in Ethiopia. By its methodological approach, this review was a narrative review, since the reviewer summarized the findings of empirical research which was conducted in different parts of Ethiopia at different time regarding challenges and opportunities for Women Empowerment in Leadership Position. As per stated by Philip (2009), in a narrative review methodology, selected studies are compared and summarized, and results are based on a qualitative rather than a quantitative approach. Hence, the findings of the reviewed studies were paraphrased, narrated and presented thematically.

The reviewed studies included both published and unpublished research works. The published research articles were collected from the internet by entering the search terms and phrases such as 'Women leadership in Ethiopia', 'Challenges of Women leadership in Ethiopia', 'opportunities of Women leadership in Ethiopia' into the Google search engine and other sites of interest.

Only full length and open access research articles were considered for the review. Consequently, a total of seven (7) published research articles were accessed from different journals such as the International Journal of Science and Research, Australian Journal of Business science Design and Literature, International Journal of Educational Administration and Policy studies, Asian Journal of Humanity, Art and Literature, International Journal of Current Research, Global Journal of Management and Business Research, and International Journal Business and Leadership. And five (5) theses works with an academic rating of very good and above were selected for this review. In addition, unpublished $\mathrm{PhD}$ dissertation was accessed from Indira Gandhi National Open University (Ignou). Hence, a total of 13 research works were reviewed. The small amount is somewhat of a limitation in a narrative approach, but the researcher is happy that important areas were covered.

The reviewed studies were conducted between 2011-2018 in different parts of Ethiopia and the regional distribution of the reviewed studies indicated that; three researches were conducted in Amahara Regional State (Tigray, Selected woredas of Machew, and Amhara region as a whole, as a case), two researches were conducted in Oromiya Regional State (Jimma Zone, Bedele Town Administration), two researches were conducted in Southern Regional state (Bench Maji Zone and Dilla), two research were conducted in Addis Ababa, and the remaining four research were conducted by taking Ethiopia on the whole, as a case. Besides, all the studies were conducted at different sector; such as Financial Institutions, Public sectors, and Higher education Institutions of Ethiopia.

\section{Findings}

In this section, the findings from reviewed studies regarding constraints/factors and opportunities of Women Empowerment in Leadership Position in Ethiopia are briefly discussed.

\section{Challenges of Women Empowerment in Leadership Position in Ethiopia Lack of Academic Qualification}

Since education is the basic tool to bring the desired societal change in politics, economy, health, equality, development; providing quality education without discrimination provides opportunity for women actively participate in the development process and enhances the mobility of women in the society.

But, discrimination of women in education creates inequality between males and females and this process persists in their lives and will have an impact in their future achievement. Netsanet (2013) performed study on challenges and opportunities of Women to be leaders in Selected Governmental Secondary Schools of Addis Ababa city government education bureau and found that low educational background of women were barriers for the low participation of women principals in secondary schools. With this support the report of Central Statistical Agency (2012) revealed that the number of women in different educational levels is so low as compared to males. Besides, the 2011 report of contribution of charities for the achievement of MDGS in Ethiopia (2011) indicated that; because of various problems, Ethiopian women also suffer from discriminations and there are fewer girls' enrolment and high dropout rates in schools. In line to this the Hiwot (2017) studied challenges and prospects of women managers in financial Sector of Ethiopia and her finding indicated that; lack of updating their knowledge 
was among the Challenges faced by women managers in the financial sector. Also Getachew (2014) investigated opportunities and challenges of women's empowerment in leadership position in Tigray regional state and suggested that even though there is a little bit progress, women's empowerment in leadership position growth rate is insignificant compared to the growth rate of women in expert staff and this is related low level of women pursuing higher education. Besides, Gojjam and Manjit(2016) studied on factors affecting women's participation in leadership and management in selected public higher education institutions in Amhara region and found that Low academic qualification is among the major barriers stifling women to assume leadership positions. Which is supported by the findings of Brikti (2013) and stated that; educational gap is one of the major factors for law participation of women in leadership position. Even though the company males are dominating in number on some fields of education like information technology, electrical engineering, which is one the necessary fields for ethio-telecom company operation and where also more staffs are found, the numbers of women who are working on that division are low as compared to the other division due to their educational status.

\section{Gender Stereotyping}

Stereotyping behaviour provokes gender role socialization in the workplace. Stereotypes about groups of people are often inaccurate or they are an overgeneralization does not apply to the individual group member who is being targeted; thus it become the basis of faulty reasoning, leading to biased feelings and actions, disadvantaging others, not because of what they like or what they have done, but because of the groups to which they are deemed to belong. Hiwot(2017) in her finding revealed that; all decisions are made only in one angle (male part) since women are out of the decision making places, which makes unable to express their idea or issue from the different women perspective; which leads to inferiority for both women who are already in leadership position and the overall women staffs of the company. Besides, which affect their confidence and unable to express their idea freely. Gojjam and Manjit (2016) in Amhara region and found that women's are underrepresented in their leadership position, and hence stereotyping is among the major barriers stifling women to assume leadership positions. Also, As Hoobler (2011) concerning stereotyping stated that the 'glass ceiling' explanations focus on discrimination due to many, varied causes, such as sex role stereotyping where individuals tend to associate male characteristics and consequently men with leadership positions also called the "think leader, think male' phenomenon. Fatherly, as per scholars substantial empirical evidence that illustrate that they associated successful leaders with stereotypically male attributes such as independence, assertiveness, and decisiveness and hence, due to stereotyping of what women 'are like' in the workplace do not match with the male leadership archetype, women are not considered for or are judged to be ill suited for the top jobs.

\section{Over Burden of Domestic Responsibility}

Among the key challenges faced by women in leadership roles was the struggle to balance the gendered responsibilities of homecare against responsibilities outside of the home, and the restrictions and expectations imposed upon them by family members and by themselves. Hiwot (2017) in her findings disclosed that family responsibility affected women managers as they advance in their career. Although the government at any level is committed to raise women participation in leadership, participation of women in vacant and nomination leadership is limited due to family and home related reason of women. Though equal opportunity of participations are given for empowering women, due to high workload at home \& family related factors, women have shown little willingness to participate in the given vacancy and nomination in leadership positions (Getachew 2014).

Chalchissa and Emnet (2013) stated that despite women's participation in the economic sphere is narrow and largely limited to domestic work and low paying menial jobs in the formal economic sphere, making them largely dependent on men for economic support for themselves and their families, their valuable contribution has never been calculated in the national GDPs globally. However, women can prove to be a valuable resource and an asset for the country with the abilities like handling multiple tasks simultaneously, which might not be that easy for male employee standing. Miressa (2012) performed study on practices and challenges of women in leadership and development activities of some selected woredas of Bench Maji Zone and revealed that women under representing in leadership position in almost all sectors due to relatively women have less freedom because of their family responsibility and lack of necessary qualifications and skills to fill position of responsibility.

Also Nejat (2017) studied challenges contributing to representation of women in leadership positions of the $\mathrm{CBE}$, in Ethiopia and found that over burden of women by household responsibilities is most important constraints, among others, that hinder women advancement to leadership positions in CBE. And hence, Women in the banking sector still face considerable barriers as they proceed into senior and executive leadership levels when compared to their male counterparts. The industry remains a male dominated and glass ceiling still remain intact. Netsanet (2013) investigated Challenges and Opportunities of Women to be Leaders in selected Governmental; and her finding showed that, fear of balancing family and professional work is among the barriers 
for the low participation of women principals in secondary schools. Besides; Elsi (2013) stated that Society's perception of women's place is still associated to their home and family which puts limitations on their working careers. It is still generally accepted that a woman plays the "motherhood" role and caregiver to family. In contrest, men are perceived as the breadwinner and given head of the family role which is related to Societal factors that effected on various dimensions of life and cannot be easily controlled and Hence, they are the most difficult and time taking factors to change. Gakuba (2014) in his finding revealed that difficulty in playing the triple role i.e., combining family management, work and social relations and technology that does not able to lightening the woman's work.

\section{Lack of Networking Opportunities}

Many female academic staffs are relatively isolated, due to weak connections with male informal networks as well as low level of networking among female staff across different departments and colleges. This affects their access to information on a range of issues, including for instance scholarships (Affirmative action and gender equality in 13 universities in Ethiopia; policy brief 3/2015), besides; having an early opportunity to work close to senior people can give future female managers access to a network of influential contacts. Which contacts can expose young managers to how an organization operates both on a formal and informal basis, thus providing valuable business insight. Getachew (2014) in his finding suggested that developing strong Women's network enables them to be effective in their leadership position and decision making ability; which on the other hand showed as there is lack of women's network at their working environment. Also Hiwot(2017) in her study found as lack of networking challenged women for their leadership position and fatherly revealed that Informal network of men is the main contributory factor for their participation in leadership, particularly where there are no criteria for recruiting leaders for leadership positions; accordingly despite competence, performance, qualification and experiences of individuals, relationship through informal network create a great opportunity for men to come to the leadership positions. Even though women are well experienced and qualified, they might be dominated in the leadership positions because of the established network of men. This is due to the fact that they are unable to devote their full time and energy to paid work because of their family responsibilities. Besides, Gelashe, et,.al.(2015) studied on Assessment of factors Affecting women participation in managerial Positions in Selected Public organizations in Jimma Zone, Oromia, Ethiopia and found that From Societal factors affecting women's participation in managerial positions is around $87 \%$ of respondents responded Men are seen as decision makers and around $81 \%$ of the respondent replied women's lack of social network as the obstacle for women's participation in managerial positions; which means they are not actively participating in extra activities in and out of their organization. The author further indicated in the responses of interviewed informants, women are exposed to double responsibilities one in office and the other at home and hence of they have no extra time to socialize with many people and suffer from lack information concerning.

\section{Lack of Confidence}

Adonay et,al.,(2014) studied on assessment of the participation of women in public administration, specifically in Tigray and revealed $83.4 \%$ respondents state that most women don't have an experience of leadership, while according to the $16.6 \%$ respondents; most women's are experienced of leadership. Similarly, the participants of her focused group discussion and interviewed refer that majority women's of the woreda's have no an experience of leadership and most women are found in the supportive and lower work positions; hence lack of confidence is among the main constraint responsible to this. And also Women who aspire to become leadership are more likely to response lowered aspiration than men (Birhanu, 2011). And also lack of confidence in their work place is factors that hindered women from participation of higher educational leadership position (Gojjeb and Manjit 2016).

Getachew (2014) in his finding revealed that personal factors such as, informal network of men which favors them to be leaders, lack of interest due to women's self image is low: i.e, perceived themselves as do not have skill, lack of experience, lack of competency and fear of hardship is among factors that hindered women leadership and management participation at higher education institution. Besides, Gelashe, et,al.(2015) studied on assessment of factors affecting women participation in managerial positions in selected public organizations in Jimma Zone; stated that lack of confidence is among the Women's personal factors affecting their participation in managerial positions. Also Birhanu (2013) studied on Challenges and opportunities of educating women's leadership and action in their mission for emancipation and change and stated that in Ethiopia there is lack of confidence in women's capabilities of leader ship in which it inhibit women's from participating in leadership positions.

Rahel (2013) stated that women manager faced lack of self-confidence and have a tendency not to accept their ideas and suggestions; question of freedom of being equally competing and on assigning in very challenging and knowledge based tasks with those who are affiliated with politics. 


\section{Other Factors}

Apart from the aforementioned major challenges, there are also other constraints which are specific to diverse study areas. For instance, unclear promotion procedure, lack of long year experience, religious practice, lack of support from family/husband, company recruitment and promotion practice, cultural values are among responsible factors that hindered women in participation of managerial position (Gelashe, et,al. 2015; Birikti 2014; Adonay 2014).

Gojjeb and Manjit (2016) investigated factors that facilitate or constrain women to participate in leadership and management and also found that Patriarchy, Lack of support system at work, and Lack of role model are the major barriers stifling women to assume leadership positions.

As Inadale (2014) studied on Factors that affect Women Participation in Leadership and Decision Making Position of Bedele town Oromia; Lack of acquisition of the necessary experience for taking part in public decision-making, continuation of the negative attitudes regarding women's ability to lead and govern, Lack of role models of women leaders for young women and girls are among factors that challenged women in assuming their leadership position. The finding of Getachew (2014) also revealed that; even though there is a little bit progress, women's empowerment in leadership position growth rate is insignificant compared to the growth rate of women in expert staff, and he was further identified that the major causes that hindered women's having leadership position were socio-cultural, personal and institutional barriers, like home and family responsibility, lack of monitoring and evaluation and related issues are the concern.

Beside Tefera (2018) studied Nature of Women Empowerment in Ethiopia, constitutional and policy provisions and stated that low level of literacy and lack of awareness, absence of institutions and institutional capacities in implementing gender based policy, politicization of women's organization and deep rooted socialcultural malpractices are factors that hindered women empowerment. In Ethiopia, culture has its own influence; men are expected to be courageous, competent, domineering and to show qualities of leadership while women are submissive, conservative and shy (Genet and Haftu, 2013). Besides, Ethiopia is one of the developing countries where women are facing political, social and cultural challenges that undermine their human worth and dignity and also women's' are suffering from economic poverty, social discrimination, political disenfranchisement, and cultural subjugation which ultimately affect their leadership position negatively (Helina, 2015).

\section{Opportunities for Women Empowerment in Leadership Position in Ethiopia}

To ensure gender equality and to empower women in Ethiopia, the government has taken a number of measures recently which includes: affirmative action, quotas, advocacy, lobbying and awareness creation in order to increase the participation of women in the decision making structures of the country which is supported by (Adonay, et.al. 2014).

Affirmative action in Ethiopia has increased women's participation in decision making activities in various sectors. There are different strategies that address gender imbalance in leadership position in every governmental institution. Concerning institutional politics, most respondents $(86.1 \%)$ agreed that institutional politics did not hinder women from participating in leadership positions, besides the participants of the focus group discussion and interview supported the above findings in that the organizational politics are encouraging and empowering them to actively participate in decision making activities and leadership positions(Genet and Haftu 2013).

The finding of Netsanet (2014) revealed that currently there are opportunities that encouraged the participation of women principals in governmental secondary schools specially in hiring and gender policies were updated and reviewed regularly, also there were women affairs departments at federal, regional and woreda's levels, women could get support from colleagues to be familiar with school culture, and the criteria that were used to select candidates for secondary school principals, especially implementing affirmative action (quota system), encouraged the participation of women in leadership position. Besides, Getachew (2014) in his finding stated that; even though the gender policy strategies demand other mechanisms in order to narrow the gendergap in key strategic positions; women have been given priority when they had the same qualification and work experiences as their male counterparts. Also, Hiwot(2017) had performed her study in financial institution and revealed that there is opportunities for women managers; different mentorship program and training is conducted, the expansion strategy of the bank is offering many top managerial positions in which most of the posts proposed to fill with women managers, besides soft ware so called Enterprise Resource Planning (ERP), which help women managers in facilitating their function. Most institutional policies are promoting and empowering women in every activity in governmental organizations. Adonay, et.al. (2014) in their study found that; the work policies are also sensitive to women and it gives priority to women; The strong commitments of the current government to promote and to empower women in every activity, institutional policies are prepared and designed based on gender mainstreaming and these policies give equal opportunity to women and men in every activities. Besides, the institutional policies give affirmative action, quota and other privileges to women. Their finding is consistent with the Ethiopian constitution, laws and policies which promote gender equality and women's empowerment. 
Also, as per the report made by Aljazeera(2018) Recently Ethiopia has downsized its cabinet, named women to half the positions and, for the first time, appointed a woman as president. These are huge milestones in Ethiopian politics. They could also mark a turning point for the country's girls as the women ministers are perhaps more likely to pursue policies that benefit girls. In addition, having women in positions of power will mean that; girls have role models they can look up to, something that's not common in the country.

\section{Conclusion and Recommendations}

The findings from the review of different studies revealed that; lack of educational qualification, gender stereotyping, over burden of domestic responsibility, lack of networking opportunity, and lack of confidence/self esteem as the major hindrances of Women Empowerment in Leadership Position in Ethiopia. Besides, unclear promotion procedure, lack of long year experience, religious practice, Patriarchy, Lack of support system at work, and Lack of role model, lack of monitoring and evaluation, economic poverty, social discrimination, political disenfranchisement, and cultural subjugation are leads to be the main challenges towards women empowerment in leadership position in Ethiopia.

And hence, those constraints need immediate action in Ethiopia especially in empowering women in their leadership position since women's are highly powerful, can hold responsibility in any direction and they are committed too. Even though, women's are involved currently at minister level still their number is small when compared to the insolvent of males; so the government, Ministry of women affairs and any other concerned body has to give attention; on the above raised constraints, concerning women education the government make avail it for all equally besides there is affirmative action until preparatory level but many women's interrupted their education due to different problem that discussed as challenged above and small number of them join higher institution. At university level they faced many challenges, i.e lack of confidence, and most of them wouldn't succeeded because there is no special support provided for the at this level, even if the graduated their score is not as much satisfactory and they couldn't be competent in the market and stay dependent. Not only this even at their work place, they have no role model because previously women's are highly victimized and priority was given only for male; our couture, lack of support at work place, and at home by itself was among the main challenge.

So, to come-up with these all challenges all the community has to be aware of such case because the government or ministry of women's affair couldn't sole those challenge lonely unless the whole community involvement.

By the side of the government many activities was done even though it couldn't brought the demanded change towards empowering women's; it looks strange in seeing women president in Ethiopia, increasing women ministers to $50 \%$ and others are highly creditable today.

\section{Reference}

Addis Ababa, Apr 192019 (IPS) reported by Bethlihem Mengistu.

Adonay H., Girma T., and Hagos T., (2014), Women participation Public administration, Tigray, Ethiopia; Institutional policy success with cultural challenges, International journal of current research, vo.6, No.12, December 2014.

Birhanu, M. 2013. Challenges and opportunities of educating women's leadership and action In their mission for emancipation and change, Discrepancies between policies and practices; Adama science and Technolog University.

Birikti G.M. (2014), Assessment of factors affecting participation of women I management position; the case of Ethio-telecom, A.A, Ethiopia, Master's Thesis.

CSA (2011). Central Statistical Report on the 2011 urban employment unemployment Survey, No. 521, Addis Ababa; Central Statistical Agency.

Chelchissa A. and Emnet N. (2013), Women's Involvement as an Effective Management Tool in Decision Making in Oromia Region's Public Organization, Basic Research Journal of Business Management and Accounting.

FDRE, Central Statistical Agency (2014), Statistical Report on the 2014 Urban Employment Unemployment Survey Addis Ababa, Statistical Bulletin.

Elsi, L. (2013), Women and leadership: Factors that influence women's career success, Lahti University of Applied Sciences.

Endale A.(2014), Factors that affecting women participation in leadership and Decision making Position; Asian journal of Humanity, Arts and literature, Vol.1, No.21, 2014.

Gakuba M.JD.(2014), Challenges faced by women leaders in Rwandan local governments

Gelashe Uk.J, Chalchissa A, Kaushi k.k, and Geremew M.(2015), Assessment of factors Affecting women participation in managerial position; in selected public organization of Jimma Zone, Oromia, Ethiopia; Global journal of management and business research; Vol.15, No.1, 2015. 
Genet, G. and Haftu, H. (2013), Impact of gender roles on women involvement in functional adult literacy in Ethiopia: The international Journal of Social Sciences, 28th March 2013, vol.9.No 1.

Getachew N. (2014), Investigate opportunities and challenges of women's empowerment in Leadership position, Endamohi woreda, Tigray regional state, Ethiopia; PhD Disertation.

Gojjam A. and Manjit S.(2016), Factors affecting women participation in leadership and Management, In selected public higher education Institute, Amhara Region, Ethiopia, Australian journal of Business science design and literature; Vol.9, No. 1, 2016.

Helina B. (2015), Final Report National Assessment: Ethiopia Gender Equality and The Knowledge Society.

Hiwot B.(2017), Assessing the challenges and prospects of women managers in financial sector; The case of DBE, Master's Thesis.

http://www.ipsnews.net/ on line sources, reported by, Aljazeera.

Jenny Hoobler et al , (2011), Women's Underrepresentation in Upper Management, New Insight in Persistent Problem.

Mekasha k.(2015), Women's role and their style of leadership, A.A, Ethiopia; International journal of educational administration and policy studies; vol.9, No.3, November 2015.

Millennium development goals in Ethiopia: lessons for the sustainable development goals, 2011; Addis Ababa, Ethiopia.

Miressa Y.(2012), Practice and challenges of women in leadership and development activities of Bench Maji Zone; SNNE, Ethiopia, International journal of science and and Research, ISSN; 2319-7064, 2012.

Nejat N.(2017), Challenges contribute to the representation of women in leadership position; the Case of CBE, A.A, Ethiopia, Master's Thesis.

Netsanet W. (2013), Challenges and Opportunities of women to be leader in selected governmental Secondary school of A.A; Master Thesis.

Panigrahi, MR. (2013), Perception of secondary school stakeholders towards women representation in educational leadership in Harari region of Ethiopia. International women online journal of distance education. Vol.2, No. 1, January 2013

Philip, M.(2009), Guidelines for writing a Review Article. Retrieved from (http://www.plantscience.ethz.ch/education/Masters/courses/Scientific_Writing) accessed on 17, January 2016.

Revised Family Law (2000); Revised Criminal Code (2005); and Change Package (2006) of The FDRE Constitution, Ethiopian Women Development,

Rahel A.(2013), Opportunities and challenges of women managers in selected organizations, A.A, Ethiopia, Master's Thesis.

Tefera A.(2017) Nature of Women Empowerment in Ethiopia: Constitutional and Policy Provisions; Dilla University.

The Federal Democratic Republic of Ethiopia 1995, The constitutions of the federal republic of Ethiopia, Addis Ababa.

United Nation Development Assistant Framework 2012, Joint program on gender equality and women' empowerment

United Nations Global Compact 2011, Women empowerment, United Nations entity for gender equality and the empowerments of women. Journal of Women Empowerment Principle, 1-4 